\title{
AS BOLSAS DE ASSISTÊNCIA ESTUDANTIL NA FORMAÇÃO EM ENGENHARIA: O CASO DO CEFET/RJ
}

Thiago Tavares de Barros - thiago.barros@cefet-rj.br

CEFET/RJ - UFF / LATEC Mestrado Profissional em Sistemas de Gestão

Av. Maracanã, 229 - Bloco - DIRAP

20.271-110 - Rio de Janeiro - RJ

Cristina Gomes de Souza - cristina.souza@cefet-rj.br

CEFET/RJ - Departamento de Engenharia de Produção

Av. Maracanã, 229 - Bloco E - Sala E505.04

20.271-110 - Rio de Janeiro - RJ

Resumo: Nas últimas décadas foram estabelecidas diversas políticas a fim de expandir o ensino superior no país e a democratização do acesso nas Instituições Federais de Ensino Superior (IFES). Apesar do aumento do número de vagas, as altas taxas de evasão continuam a ser um desafio para formação em engenharia. Com o propósito de minimizar as desigualdades sociais e proporcionar condições de permanência nas IFES, foi criado o Programa Nacional de Assistência Estudantil (PNAES). Diante desse cenário, o presente trabalho tem por objetivo descrever a evolução das ações e regulamentações voltadas para a assistência estudantil no Brasil e apresentar dados da implantação do PNAES no tocante às bolsas concedidas para alunos dos diversos cursos de Engenharia do Centro Federal de Educação Tecnológica Celso Suckow da Fonseca - CEFET/RJ. Trata-se de um estudo descritivo que foi desenvolvido a partir de pesquisa bibliográfica, pesquisa documental e levantamento de dados. Os resultados mostram a distribuição das bolsas de assistência estudantil considerando a modalidade do curso, gênero e etnia declarada. Espera-se que esse trabalho possa contribuir para estimular reflexões, ampliar discussões e promover maior sensibilização quanto à importância e necessidade do fortalecimento das políticas de assistência estudantil como mecanismo para reduzir a evasão nos cursos de engenharia.

Palavras-chave: Assistência estudantil. PNAES. Formação em engenharia.

\section{INTRODUÇÃO}

A formação em Engenharia é fundamental para o desenvolvimento tecnológico de um país proporcionando infraestrutura, bens e serviços que contribuem para a melhoria da qualidade de vida da sociedade. A importância da formação em Engenharia é reforçada diante da chamada Sociedade do Conhecimento, caracterizada pelo ritmo acelerado de inovações, velocidade e intensidade das mudanças, forte interconexão entre os países e uso intensivo de tecnologia, o que demanda, cada vez mais, pessoal altamente qualificado (BORGES e ALMEIDA, 2013).

Diante desse cenário, o governo brasileiro vem adotando medidas de incentivo à formação em Engenharia. Nas últimas décadas podem ser citados diversas iniciativas tais como o Programa de Desenvolvimento das Engenharias - PRODENGE, abrangendo dois subprogramas: Reengenharia do Ensino de Engenharia - REENGE e Redes Cooperativas de 
Pesquisa - RECOPE (1995); PROMOVE - Engenharia no Ensino (2006); iNOVA Engenharia (2006); e Programa Brasileiro de Aceleração Tecnológica em Engenharia - BrasilTEC (2009). Visando à mobilidade internacional de estudantes de Engenharia, foi implementado o programa Brasil France Ingénieur Technologie - Brafitec (2002). Embora não específico para a área de Engenharia, o Programa Ciência Sem Fronteiras (2011) também concebia a Engenharia como área prioritária, privilegiando a realização de intercâmbios internacionais por parte de docentes e discentes de graduação e pós-graduação. Maiores informações sobre os objetivos e resultados desses programas podem ser obtidas em Longo (2004) Mota e Martins (2008), Cordeiro et al. (2008) e Livore, Cechin e Pilatti (2020).

Além dessas várias ações voltadas para melhoria da formação em Engenharia, acrescentase o enfrentamento de outros desafios referentes ao ensino superior brasileiro como a expansão do número de vagas, a oferta de cursos em regiões remotas do país, a garantia da qualidade do ensino e a promoção de inclusão social pela educação (MOTA e MARTINS, 2008). Nesse sentido, vale destacar o Programa de Apoio a Planos de Reestruturação e Expansão das Universidades Federais - REUNI (2007), bem como, outras ações envolvendo o Fundo de Financiamento ao Estudante do Ensino Superior - FIES e o Programa Universidade para Todos - ProUni. Enquanto o REUNI promoveu a criação de novos cursos e o aumento de vagas nas universidades federais, propiciando o acesso de estudantes de baixa renda e de regiões antes não contempladas por universidades públicas (FAVATO e RUIZ, 2018), o FIES e o ProUni passaram a facilitar e permitir o ingresso de estudantes carentes no ensino superior privado (NETO, 2018).

As ações do governo, somadas às demandas do mercado por profissionais da área tecnológica, acabaram promovendo um aumento da formação em engenharia no Brasil. Conforme apontado por Oliveira et al. (2015), observa-se que a partir de 1996 houve um grande crescimento na quantidade de cursos de engenharia no país, tanto em instituições públicas quanto privadas. De acordo com os dados mais recentes disponibilizados pelo Censo da Educação Superior, atualmente existem 6.118 cursos na área de Engenharia, Produção e Construção com um total de 1.170.660 matrículas (INEP, 2019).

Apesar do aumento do número de vagas ter permitido maior acesso aos cursos, as altas taxas de evasão continuam a ser um desafio para formação em engenharia (OLIVEIRA, 2013; SACARO, FRANÇA e JACINTO, 2019). No âmbito das Instituições Federais de Ensino Superior (IFES), a promulgação da Lei de Cotas em 2012 - em que 50\% das vagas passaram a ser destinadas a alunos oriundos de ações afirmativas (estudantes de escolas públicas, com subcotas para aqueles cujas famílias possuem renda per capita igual ou inferior a um salário mínimo e meio; e/ou autodeclarados pretos, pardos ou indígenas) - fez com que a preocupação com a evasão se tornasse ainda maior, reforçando a necessidade de políticas assistenciais destinadas a dar apoio a esses estudantes (SOUSA e NASCIMENTO, 2019).

Acrescenta-se que o próprio Sistema de Seleção Unificada - SISU, apesar de todos os seus méritos como mecanismo de acesso às IFES, trouxe novas demandas no tocante à permanência nos cursos ao facilitar a aprovação de candidatos em instituições distantes de sua cidade de origem demandando custos adicionais de moradia, alimentação, transporte, etc. (RECKTENVALD, MATTEI e PEREIRA, 2018). Dados relativos ao ano de 2017, por exemplo, mostram que 31.881 (cerca de 10\%) dos novos alunos das instituições federais se matricularam em uma unidade da federação diferente daquela de sua residência (INEP, 2018).

Assim sendo, diante de um cenário de expansão do ensino superior brasileiro e visando atender a demanda de ampliação das condições de permanência dos alunos nas instituições públicas federais, foi criado o Programa Nacional de Assistência Estudantil - PNAES através do Decreto $n^{\circ} 7.234$, de 19 de julho de 2010. De acordo com o PNAES, cabe a cada instituição 
a definição de critérios e a seleção dos alunos a serem beneficiados pelo programa. Recktenvald, Mattei e Pereira (2018) apontam que o PNAES pode ser entendido como uma tentativa de consolidar o binômio Acesso-Permanência nas IFES, sendo necessário haver uma complementariedade entre ambos. Ainda segundo os autores, sob uma perspectiva funcionalista, o "PNAES tem, desde o seu escopo inicial, um papel essencialmente social, baseado na solidariedade".

A partir desse contexto inicial, o presente trabalho tem por objetivo descrever a evolução das ações e regulamentações voltadas para a assistência estudantil no Brasil e apresentar dados da implantação do PNAES no tocante às bolsas concedidas para alunos dos diversos cursos de Engenharia do Centro Federal de Educação Tecnológica Celso Suckow da Fonseca CEFET/RJ, considerando a modalidade de curso, gênero e etnia declarada.

Espera-se que esse trabalho possa contribuir para estimular reflexões, ampliar discussões e promover maior sensibilização quanto à importância e necessidade do fortalecimento das políticas de assistência estudantil como mecanismo para reduzir a evasão nos cursos de engenharia.

\section{ASSISTÊNCIA ESTUDANTIL NO BRASIL}

A implementação de iniciativas voltadas para assistência estudantil não constitui um fenômeno recente. Essa seção apresenta a evolução dos principais marcos da assistência estudantil e o estágio atual com a criação do PNAES.

\subsection{Histórico da assistência estudantil}

As origens da assistência estudantil no Brasil datam do final da década 1920 e início da década de 1930 (IMPERATORI, 2017). De acordo com Poener (2004), em 1929 foi criada, por um grupo de alunos universitários, a fundação da Casa do Estudante do Brasil, com sede na cidade do Rio de Janeiro, tendo como objetivo auxiliar estudantes carentes. Em 1931, o então presidente da república Getúlio Vargas doou, por intermédio do Decreto no 20.559 de 23 de outubro de 1931, recursos provenientes de fundos angariados para a Casa do Estudante do Brasil.

\footnotetext{
Considerando que, no momento, a "Casa do Estudante do Brasil" é a iniciativa de filantropia privada que mais de perto consulta aos interesses da nacionalidade de vez que os seus fins abrangem as mais justas reivindicações da classe acadêmica, e concorrem de modo preponderante para a solução de um dos fundamentais problemas do país, cada vez mais confiante na formação das gerações vindouras.
}

A partir de 1931, entraram em vigor um conjunto de decretos denominados de "Reforma Francisco Campos" (SHIROMA, MORAES E EVANGELISTA - 2007). Dentre esses, o Decreto $\mathrm{n}^{\circ} 19.851$, de 11 de abril de 1931 pode ser considerado o mais importante, pois tratava do Estatuto das Universidades Brasileiras, sendo um dos primeiros marcos da regulamentação do ensino superior no país (PALAVEZZINI, 2014). Esse decreto traz em seu artigo 100, parágrafo IV, a primeira regulamentação da assistência estudantil no Brasil.

$\S 4^{\circ}$ As medidas de providência e beneficência serão extensivas aos corpos discentes dos institutos universitários, e nelas serão incluídas bolsas de estudo, destinadas a amparar estudantes reconhecidamente pobres, que se recomendem, pela sua aplicação e inteligência, ao auxílio instituído. 
O estatuto foi incorporado a Constituição Federal de 1934, estava explícito em seu artigo 157 (BRASIL, 1934).

Art. 157 - A União, os Estados e o Distrito Federal reservarão uma parte dos seus patrimônios territoriais para a formação dos respectivos fundos de educação. $\S 2^{\circ}$ Parte dos mesmos fundos se aplicará em auxílios a alunos necessitados, mediante fornecimento gratuito de material escolar, bolsas de estudo, assistência alimentar, dentária e médica, e para vilegiaturas.

Em 1938 foi criada a União nacional dos Estudantes (UNE), que passou a ter a sua sede na Casa dos Estudantes do Brasil, no Rio de Janeiro (POERNER, 2004). Albuquerque (2005) diz que a UNE foi de extrema importância na luta das políticas publicas no que tange a assistência estudantil no Brasil.

Os artigos 166 e 172 da Constituição Federal de 1946, trata explicitamente da assistência nas instituições de ensino do Brasil.

Art. 166 - A educação é direito de todos e será dada no lar e na escola. Deve inspirarse nos princípios de liberdade e nos ideais de solidariedade humana.

Art. 172 - Cada sistema de ensino terá obrigatoriamente serviços de assistência educacional que assegurem aos alunos necessitados condições de eficiência escolar.

Palavezzini (2014) diz que a Lei no 4.024 fixou diretrizes e Bases para a educação Nacional e que a referida lei trouxe em seus artigos 90 e 91, título XI, as questões envolvendo a assistência social escolar.

Art. 90. Em cooperação com outros órgãos ou não, incumbe aos sistemas de ensino, técnica e administrativamente, prover, bem como orientar, fiscalizar e estimular os serviços de assistência social, médico-odontológico e de enfermagem aos alunos.

Art. 91. A assistência social escolar será prestada nas escolas, sob a orientação dos respectivos diretores, através de serviços que atendam ao tratamento dos casos individuais, à aplicação de técnicas de grupo e à organização social da comunidade.

Em 1966, a UNE é suspensa por intermédio do Decreto $\mathrm{n}^{\circ} 57.634$, de 14 de Janeiro de 1966. Em 1968, foi promulgada a Lei $\mathrm{n}^{\circ} 5.540 / 68$, reformulando a atividades de nível superior no Brasil.

Em 1970, o governo federal criou o Departamento de Assuntos Universitários (DAU), departamento ligado ao Ministério da Educação (MEC), que tinha como objetivo, manter as políticas de assistência estudantil para a graduação em nível nacional. Palavezzini (2014) diz que em no final dos anos 80, o DAU foi extinto e as ações assistenciais ficaram fragmentadas, sendo as próprias Instituições Federais de Ensino Superior (IFES), responsáveis por seus programas assistenciais estudantis, que eram mantidos com seus próprios recursos.

\subsection{Contornos atuais da assistência estudantil}

Como visto anteriormente, as ações para implantação de uma política assistencial estudantil não são recentes. Atualmente o governo federal oferece a comunidade acadêmica a possibilidade de ingresso nos programas de assistências estudantis por meio do Plano Nacional de Assistência Estudantil (PNAES), que apóia a manutenção dos alunos de baixa renda que estão cursando o nível superior de forma presencial nas IFES.

O PNAES foi lançado por meio da Portaria Normativa 39, de 12 de dezembro de 2007 e teve seu início de atividades em 2008. Em seu artigo $2^{\circ}$, a referida portaria destaca que as ações de assistência estudantil do programa devem ser efetivadas através de atividades de ensino, 
pesquisa e extensão, sendo destinadas a estudantes de cursos de graduação das IFES. São contempladas como ações de assistência estudantil: moradia estudantil; alimentação; transporte; assistência à saúde; inclusão digital; cultura; esporte; creche; e apoio pedagógico.

Em 2010 o PNAES passou a ser regido pelo Decreto $n^{\circ} 7.234$, de 19 de julho de 2010, passando a ter maior proteção jurídica (IMPERATI, 2017). Com o advento do Decreto, os seus os objetivos do programa passaram a ser, como demonstrado no artigo $2^{\circ}$.

\author{
Art. $2^{\circ}$ São objetivos do PNAES: \\ I - democratizar as condições de permanência dos jovens na educação superior pública \\ federal; \\ II - minimizar os efeitos das desigualdades sociais e regionais na permanência e \\ conclusão da educação superior; \\ III - reduzir as taxas de retenção e evasão; e \\ IV - contribuir para a promoção da inclusão social pela educação.
}

Para Vasconcelos (2010), o PNAES é resultado de grande esforço e foi consolidado depois de inúmeras lutas travadas para manter a conquistar a estabilidade assistencial no Brasil, que busca o direito social voltado ao estudante de baixa renda e a igualdade no desenvolvimento acadêmico nas IFES. Para Imperatori (2017), o PNAES é um marco histórico para a política assistencial, pois permite definir as áreas de atuações e é um referencial para os programas e projetos desenvolvidos pelas instituições federais do Brasil.

Finatti et al. (2007) destaca dizendo que a assistência estudantil vai além da área de direitos humanos nas instituições. $\mathrm{O}$ autor reforça dizendo que, a assistência social compreende mecanismo de acesso a saúde, instrumentos pedagógicos para desenvolvimento acadêmico, acompanhamento de políticas educativas especiais, além das necessidades básicas dos alunos, tais como alimentação, moradia, deslocamento e auxílio financeiro.

\title{
3. METODOLOGIA
}

Esse trabalho apresenta natureza descritiva com uma abordagem quantitativa. Conforme definido por Flick (2006), são estudos que utilizam procedimentos e dados quantitativos na abordagem investigativa. Especificamente foram adotados os seguintes procedimentos incluindo o estudo de caso realizado: pesquisa bibliográfica; pesquisa documental; e levantamento de dados em órgãos do governo federal.

A pesquisa bibliográfica foi utilizada para contextualização da problemática e fundamentação da questão teórica. Nessa etapa buscou-se publicações de assuntos relacionados à formação em engenharia, políticas de acesso ao ensino superior, assistência estudantil, evasão escolar e outros aspectos sociais envolvendo as IFES.

A pesquisa documental abrangeu a consulta de leis, decretos, programas e relatórios governamentais relacionados à assistência estudantil e ao ensino superior, em especial, à área de Engenharia. Também foram consultados documentos institucionais do CEFET/RJ, uma vez que foi a unidade de análise do estudo de caso.

Por fim, foram realizados levantamentos em sítios oficiais do governo federal, bem como, na base de dados do CEFET/RJ. Esses levantamentos tiveram por objetivo a obtenção de estatísticas e outros dados abertos a comunidade. Em especial, as consultas foram feitas nos sítios do MEC-INEP e do Portal da Transparência.

Complementando o estudo, foram utilizados dados secundários, oriundos de outras publicações relacionadas ao tema, de modo a contribuir e enriquecer a análise dos resultados, reforçando a importância do auxílio estudantil para os alunos de baixa renda na rede pública. 


\section{RESULTADOS: O CASO DO CEFET/RJ}

\subsection{Contexto histórico e aspectos institucionais}

O CEFET/RJ é uma instituição centenária, tendo sido criada em 1917, como Escola Normal de Artes e Ofícios Wenceslau Braz, incumbida de formar novos professores, mestre e contramestres para o ensino profissional. Ao longo dos anos, a instituição passou por diversas mudanças como detalhado na tabela a seguir.

Quadro 1. Marcos regulatórios referentes à institucionalidade do CEFET/RJ

\begin{tabular}{|c|l|}
\hline 1917 & $\begin{array}{l}\text { Escola Normal de Artes e Ofícios Wenceslau Braz : incumbida de formar novos } \\
\text { professores, mestre e contramestres para o ensino profissional }\end{array}$ \\
\hline 1937 & $\begin{array}{l}\text { Escola Técnica Nacional: Liceu destinado a ensino profissional de todos os } \\
\text { ramos e graus }\end{array}$ \\
\hline 1978 & $\begin{array}{l}\text { Escola Técnica Federal Celso Suckow da Fonseca: objetivos conferidos as } \\
\text { Instituições de Ensino Superior. Torna-se autarquia do Ministério da Educação }\end{array}$ \\
\hline 1994 & $\begin{array}{l}\text { Centro Federal de Educação Tecnológica Celso Suckow da Fonseca - CEFET: } \\
\text { padronização das escolas técnicas }\end{array}$ \\
\hline
\end{tabular}

Fonte: Elaborado pelo próprio autor

Em 2008 foi instituída a Rede Federal de Educação Profissional, Científica e Tecnológica com a transformação dos antigos CEFETs em Institutos Federais de Educação, Ciência e Tecnologia, ficando apenas o CEFET/RJ e o CEFET/MG como centro federal tecnológico.

\subsection{A oferta de bolsas do CEFET/RJ}

O CEFET/RJ possui 8 campi instalados no estado do Rio de Janeiro, em específico, as unidades estão nas cidades de Nova Friburgo, Valença, Itaguaí, Nova Iguaçu, Petrópolis, Angra dos Reis e Rio de Janeiro (Campus Maracanã e Maria da Graça). Atualmente, o CEFET/RJ oferece cursos técnicos de nível médio, graduação e pós-graduação lato e stricto sensu em diversas áreas do conhecimento. $\mathrm{Na}$ área de Engenharia são ofertados os seguintes cursos: Engenharia Ambiental; Engenharia Civil; Engenharia de Controle e Automação; Engenharia de Produção; Engenharia de Telecomunicações; Engenharia Elétrica; Engenharia Eletrônica; Engenharia Mecânica; e Engenharia Metalúrgica.

De acordo levantamento na Plataforma Nilo Peçanha, que contém os dados das instituições vinculadas à SETEC/MEC, a instituição possui 19.471 alunos matriculados, sendo $611(3,14 \%)$ na pós-graduação, 11.757 (60,38\%) na graduação e 7.103 (36,48\%) no médio/técnico. Desse total, 7.214 são matrículas específicas nos cursos de graduação em engenharia, o que corresponde a $37,05 \%$ do número de matrículas do CEFET/RJ e $61,39 \%$ do total das matrículas da graduação. A taxa de evasão nos cursos de graduação em engenharia do CEFET/RJ é de $5,8 \%$, abaixo da taxa de evasão de $11,3 \%$ considerando todos os cursos de engenharia da referida Rede Federal de Educação Profissional, Científica e Tecnológica.

No que tange as bolsas estudantis, em 2019, a instituição disponibilizou, com recursos próprios, um total de 2.610 vagas para serem preenchidas por estudantes de diferentes níveis de ensino. O maior quantitativo de bolsas ofertadas é da modalidade assistencial. Juntas, as três modalidades deste auxílio (bolsas PAE, PAEM e PAED) somam 1.970 benefícios, refletindo o empenho por parte do CEFET/RJ em ajudar na manutenção dos alunos de baixa renda no progresso acadêmico e social. A Tabela 1 apresenta as modalidades de bolsas, valores, quantidades de benefícios concedidos com recursos próprios e as unidades responsáveis por cada tipo de bolsa. 
Tabela 1. Distribuição das modalidades de bolsas com recursos próprios do CEFET/RJ

\begin{tabular}{|c|c|c|c|c|}
\hline Bolsa & Quantidade & $\begin{array}{c}\text { Valor da } \\
\text { bolsa }(\mathbf{R} \$)\end{array}$ & $\begin{array}{c}\text { Valor total } \\
\text { por mês }(\mathbf{R} \$)\end{array}$ & Unidade Responsável \\
\hline PAE & 1.750 & 400,00 & $700.000,00$ & \multirow{4}{*}{$\begin{array}{l}\text { DIREX (Diretoria de } \\
\text { Extensão) }\end{array}$} \\
\hline PAEM & 200 & 400,00 & $80.000,00$ & \\
\hline PAED & 20 & 400,00 & $8.000,00$ & \\
\hline PBEXT & 164 & 350,00 & $57.400,00$ & \\
\hline Monitoria EM & 130 & 250,00 & $32.500,00$ & \multirow{2}{*}{ DIREN (Diretoria de Ensino) } \\
\hline Monitoria SUP & 110 & 350,00 & $38.500,00$ & \\
\hline PIBIC EM & 50 & 300,00 & $15.000,00$ & \multirow{3}{*}{$\begin{array}{l}\text { DIPPG (Diretoria de Pesquisa } \\
\text { e Pós-Graduação) }\end{array}$} \\
\hline PIBIC SUP & 100 & 400,00 & $40.000,00$ & \\
\hline Mestrado/Doutorado & 32 & $3.700,00$ & $56.400,00$ & \\
\hline PROMISAES & 10 & 622,00 & $6.220,00$ & \multirow{2}{*}{$\begin{array}{l}\text { ASCRI (Assessoria de } \\
\text { Internacionalização }\end{array}$} \\
\hline Exterior & 44 & $1.500,00$ & $66.000,00$ & \\
\hline Total & 2.610 & & $1.100 .020,00$ & \\
\hline
\end{tabular}

Fonte: Elaborado pelo próprio autor

\subsection{Bolsas assistenciais nos cursos de engenharia}

No CEFET/RJ, são 145 bolsistas assistenciais nos cursos de engenharias (2\% dos alunos atendidos), sendo 200 o total de vagas disponibilizadas para o nível superior (dados de 2020). Portanto, o percentual de bolsas preenchidas por alunos de engenharia é de $72,50 \%$. Em comparação ao total geral, essa porcentagem corresponde a 7,36\% das 1.970 bolsas assistenciais (PAE, PAEM e PAED) disponibilizadas. A Tabela 2 mostra a distribuição das bolsas assistenciais por modalidade do curso de engenharia, gênero e etnia declarada.

Tabela 2. Bolsas assistenciais por modalidade de curso, gênero e etnia

\begin{tabular}{|c|c|c|c|}
\hline Curso & Total de bolsa & Gênero declarado & Etnia declarada \\
\hline Engenharia ambiental & 19 & $\begin{array}{l}\text { - Feminino: } 12 \\
\text { - Masculino: } 7\end{array}$ & $\begin{array}{l}\text { - Branco: } 10 \\
\text { - Preta: } 1 \\
\text { - Pardo: } 7 \\
\text { - Não sabe: } 1\end{array}$ \\
\hline Engenharia civil & 27 & $\begin{array}{l}\text { - Feminino: } 11 \\
\text { - Masculino: } 16\end{array}$ & $\begin{array}{l}\text { - Branco: } 7 \\
\text { - Preta: } 4 \\
\text { - Pardo: } 13 \\
\text { - Amarelo: } 1 \\
\text { - Não respondeu: } 2\end{array}$ \\
\hline 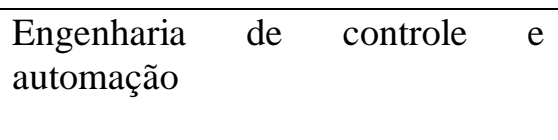 & 10 & $\begin{array}{l}\text { - Feminino: } 3 \\
\text { - Masculino: } 7\end{array}$ & $\begin{array}{l}\text { - Branco: } 2 \\
\text { - Preta: } 2 \\
\text { - Pardo: } 6\end{array}$ \\
\hline Engenharia de produção & 23 & $\begin{array}{l}\text { - Feminino: } 10 \\
\text { - Masculino: } 13\end{array}$ & $\begin{array}{l}\text { - Branco: } 9 \\
\text { - Preta: } 3 \\
\text { - Pardo: } 7 \\
\text { - Indígena: } 1 \\
\text { - Não respondeu: } 3\end{array}$ \\
\hline Engenharia de telecomunicações & 8 & $\begin{array}{l}\text { - Feminino: } 2 \\
\text { - Masculino: } 6\end{array}$ & $\begin{array}{l}\text { - Branco: } 1 \\
\text { - Preta: } 1 \\
\text { - Pardo:4 } \\
\text { - Não respondeu: } 2\end{array}$ \\
\hline
\end{tabular}




\begin{tabular}{|l|l|l|l|}
\hline Engenharia eletrônica & \multirow{2}{*}{$\begin{array}{l}\text { - Feminino: } 1 \\
\text { - Masculino: } 13\end{array}$} & $\begin{array}{l}\text { - Branco: } 6 \\
\text { - Preta: } 3 \\
\text { - Pardo: } 4 \\
\text { - Não respondeu: } 1\end{array}$ \\
\hline Engenharia mecânica & 30 & $\begin{array}{l}\text { - Feminino:7 } \\
\text { - Masculino: 23 }\end{array}$ & $\begin{array}{l}\text { - Pranco: } 13 \\
\text { - Preta: } 2 \\
\text { - Pardo: } 12 \\
\text { - Amarelo: } 1 \\
\text { - Indígena: } 1 \\
\text { - Não respondeu: } 1\end{array}$ \\
\hline Engenharia elétrica & & $\begin{array}{l}\text { - Branco: } 5 \\
\text { - Preta: } 3 \\
\text { - Pardo: } 5\end{array}$ \\
\hline
\end{tabular}

Fonte: Elaborado pelo próprio autor

Os cursos de engenharias possuem diversos materiais auxiliares para melhor desempenho dos alunos durante a graduação. Para Ramos (2019), os cursos de engenharias demandam diferentes materiais de estudos paralelos as questões teóricas. O mesmo autor reforça que, esses materiais são essenciais no desenvolvimento técnico, portanto, há um investimento necessário a fazer em suas aquisições.

Segundo Merola (2005), mesmo as instituições sendo públicas, os gastos dos alunos com passagens e alimentações são bem consideráveis, além dos custos com xerox, livros, apostilas e matérias auxiliares. A mesma autora diz que em 2005, na UFRJ, os gastos médios de 1 aluno de engenharia civil, que é integral, poderiam chegar a $\mathrm{R} \$ 3.300,00$ por ano com materiais, transportes e alimentação.

Uma entrevista com alunos concluintes de graduação da UFRJ que recebiam bolsas assistenciais evidenciou que, na ampla maioria, o auxílio financeiro disponibilizado pela instituição se mostrou essencial para conclusão de seus cursos, pois do contrário, iriam ter que trabalhar para se manterem, o que comprometeriam seus rendimentos nos seus respectivos cursos, ainda para os alunos de cursos integrais, que iriam ter que escolher outra carreira (PUC/RJ, 2008). Mostrou que a assistência estudantil, para os alunos menos favorecidos economicamente, é muitas vezes a única solução para término dos seus cursos. Diante do exposto, torna-se evidente a importância da bolsa assistencial aos alunos de baixa renda que possuem vínculo com o CEFET/RJ nos cursos de engenharias, na manutenção dos seus estudos e possibilidade igual de chegar até a conclusão (PUC/RJ, 2008).

\section{CONSIDERAÇÕES FINAIS}

Os esforços realizados nas últimas décadas visando aumentar e democratizar o acesso à educação superior no Brasil tiveram bons resultados no que se refere ao crescimento do número de cursos, vagas e matrículas. Esses resultados também são observados na área da engenharia, que é considerada estratégica para promoção do desenvolvimento tecnológico do país.

Se por um lado as políticas de acesso se mostraram bem-sucedidas, por outro a literatura aponta o problema da evasão, evidenciando a necessidade de se estabelecer políticas que garantam a permanência dos alunos. Assim sendo, é preciso haver correspondência e complementaridade entre política de acesso e permanência dos alunos no ensino superior.

O PNAES é um programa que vem ao encontro dessas demandas sociais, tornando-se ainda mais necessário a partir da adoção das cotas decorrentes de ações afirmativas nas IFES. Há que mencionar que iniciativas voltadas para assistência estudantil não constituem um fenômeno 
recente, no entanto, faz-se necessário que ações com esse propósito sejam fortalecidas e consolidadas de modo a buscar reduzir as desigualdades sociais e econômicas do país e efetivamente promover a democratização do ensino superior no Brasil.

\section{REFERÊNCIAS}

ALBUQUERQUE, Rosana Maria Marinho. A UNE e as Reformas na Universidade Brasileira. In: ARAUJO, Josimere de Omena; CORREIA, Maria Valéria Costa (org.). Reforma Universitária: a universidade pública em questão. Maceió: EDUFAL, 2005. p. 169- 193.

BORGES, M.N.; ALMEIDA, N.N. Perspectivas para engenharia nacional: desafios e oportunidades. Revista de Ensino de Engenharia, v. 32, n. 3, 2013, p. 71-78.

CORDEIRO, J.S. et al. Um futuro para a educação em engenharia no Brasil: desafios e oportunidades. Revista de Ensino de Engenharia, v. 27, n. 3, p. 69-82, 2008.

FAVATO, Maria Nilse; RUIZ, Maria José Ferreira. REUNI: política para a democratização da educação superior? Revista Eletrônica de Educação, v. 12, n. 2, p. 448-463, 2018.

FINATTI, Betty Elmer; ALVES, Jolinda de Moraes; SILVEIRA, Ricardo de Jesus. Perfil sócio, econômico e cultural dos estudantes da Universidade Estadual de Londrina-UEL - indicadores para implantação de uma política de assistência estudantil. Libertas, v. 6 e 7, n. 1 e 2, p. 246-264, jan.dez./2006, jan.-dez./2007.

FLICK, U. (2006) An introduction to Qualitive Research, 3rd ed. London: Sage.

IMPERATORI, T. K. A trajetória da assistência estudantil na educação superior brasileira. Serviço Social \& Sociedade, 129, 285-303, 2020.

INEP. Censo da Educação Superior. Brasília: MEC/INEP, 2018

INEP. Censo da Educação Superior. Brasília: MEC/INEP, 2019.

LIVORE, C.; CECHIN, M.R.; PILATTI, L.A. Programas Brafitec e Ciência sem Fronteiras: percepção de gestores dos programas no Brasil e na França. Pro-posições, v.31, p. 1-27, 2020.

LONGO, W.P. O Programa de Desenvolvimento das Engenharias. Revista Brasileira de Inovação, v.3, n.2, p. 417-447, 2004.

MEROLA, Ediane. Universidade Pública também tem preço. 2005. Disponível em: https://noticias.universia.com.br/destaque/noticia/2005/05/24/482062/publica-tambem-tem-preo.html. Acesso em: 24 jul. 2020.

MOTA, R.; MARTINS, R. As políticas do MEC para a educação superior e o ensino de engenharia no Brasil. Revista de Ensino de Engenharia, v. 27, n. 3, p. 61-68, 2008.

NETO, José Maria Franco Teixeira. Assimetrias sociais e acesso ao ensino superior ProUni e FIES no Maranhão. Tese de doutoramento. Universidade de Lisboa, Instituto Superior de Economia e Gestão - ISEG, 2018.

OLIVEIRA, Vanderli Fava de et al. A expansão do número de cursos e de modalidades de engenharia. In: XLIII Congresso Brasileiro de Educação em Engenharia, 2015, São Bernardo do Campo (SP). Anais. São Bernardo do Campo, 2015.

OLIVEIRA, Vanderli Fava de et al. Um Estudo Sobre a Expansão da Formação em Engenharia no Brasil. Revista de Ensino de Engenharia, v. 32, n. 3, p. 37-56, 2013.

PALAVEZZINI, J. (2014). Trajetória da assistência estudantil no ensino superior do Brasil. Revista: Atlante. Cuadernos de Educacion y Desarrollo. Disponivel Em: Http://Atlante. Eumed. Net/WpContent/Uploads/Assistencia. Pdf, 1-10. Acesso em: 21 jul. 2020 
POERNER, Arthur José. O poder jovem. Rio de Janeiro: Civilização Brasileira, 2004.

PUC-RJ. A Importância da Assistência Estudantil para o Estudante Bolsista. 2008. Disponível em: https://www.maxwell.vrac.puc-rio.br/20038/20038_7.PDF. Acesso em: 24 jul. 2020.

RAMOS, Pedro. Quais materiais são usados na faculdade de Engenharia Civil. 2019. Disponível em: https://blogvest.afya.com.br/quais-materiais-sao-usados-na-faculdade-de-engenharia-civil. Acesso em: 24 jul. 2020.

RECKTENVALD, Marcelo; MATTEI, Lauro; PEREIRA, Vilmar Alves. Avaliando o Programa Nacional de Assistência Estudantil (PNAES) sob a ótica das epistemologias. Avaliação: Revista da Avaliação da Educação Superior, v. 23, n. 2, p. 405-423, 2018.

SACCARO, Alice; FRANÇA, Marco Túlio Aniceto; JACINTO, Paulo de Andrade. Fatores Associados à Evasão no Ensino Superior Brasileiro: um estudo de análise de sobrevivência para os cursos das áreas de Ciência, Matemática e Computação e de Engenharia, Produção e Construção em instituições públicas e privadas. Estudos Econômicos, v.49, n.2, p.337-373, 2019.

SHIROMA, Eneida Oto; MORAES, Maria Célia Marcondes de; EVANGELISTA, Olinda. Política educacional. 4. ed. Rio de Janeiro: Lamparina, 2007.

SOUZA, Fabiana Rodrigues; NASCIMENTO, Ilca Freitas. Lei de cotas e promoção da justiça social: percepções de estudantes cotistas de um instituto federal. Espaço Pedagógico, v.26, n.3, p. 758-776, 2019.

VASCONCELOS, Natália. Programa Nacional de Assistência Estudantil: uma análise da assistência estudantil ao longo da história da educação superior no Brasil. Revista da Católica, v. 2, n. 3, p. 399$411,2010$.

\title{
STUDENT ASSISTANCE SCHOLARSHIPS IN ENGINEERING TRAINING: THE CASE OF CEFET / RJ
}

\begin{abstract}
In recent decades, several policies have been established in order to expand higher education in the country and democratize access in Federal Higher Education Institutions (IFES). Despite the increase in the number of vacancies, the high dropout rates continue to be a challenge for engineering training. In order to minimize social inequalities and provide conditions for permanence in the IFES, the National Student Assistance Program (PNAES) was created. In view of this scenario, the present work aims to describe the evolution of actions and regulations related to student assistance in Brazil and present data on the implementation of the PNAES with regard to scholarships granted to students of the various Engineering courses at the Federal Center for Technological Education Celso Suckow da Fonseca - CEFET / RJ. This is a descriptive study that was developed from bibliographic research, documentary research and survey. The results show the distribution of student assistance scholarships considering the course modality, gender and declared ethnicity. It is hoped that this work can contribute to stimulate reflections, expand discussions and promote greater awareness of the importance and need to strengthen student assistance policies as a mechanism to reduce dropout in engineering courses.
\end{abstract}

Keywords: Student assistance; PNAES; Engineering training. 